\title{
Organization of the implementation of energy efficient measures in the overhaul of residential real estate, taking «rebound effect» into account
}

\author{
Valeriy Mishchenko ${ }^{1}$, Elena Gorbaneva ${ }^{1}$,Elena Ovchinnikova ${ }^{1}$, and Kristina Sevryukova ${ }^{1,{ }^{*}}$ \\ ${ }^{1}$ Voronezh State Technical University, Moscow Avenue, 14, Voronezh, 394026, Russia
}

\begin{abstract}
The issue of including energy efficient measures in the overhaul of residential real estate has been discussed for several years. The relevance of this issue is increasing in connection with the requirements established at the state level to improve the energy efficiency of buildings. The article calculates the determination of the energy efficiency class of a residential property included in the "Regional program for the overhaul of common property in apartment buildings in the Voronezh region for 2014-2044", after the implementation of energy efficiency measures. Improving energy efficiency is a strategic goal. However, energy efficiency improvements do not always lead to energy savings due to the "rebound effect". Therefore, it is necessary to organize the implementation of energy-efficient measures during the overhaul of residential real estate and the implementation of energy-saving programs (municipal, regional, state, industry).
\end{abstract}

\section{Introduction}

Residential properties are one of the main consumers of energy and require measures to improve their energy efficiency. One of the solutions to this problem is to carry out energyefficient capital repairs, which will allow owners to save on costs, which will further reduce utility costs by about $20 \%$, as well as significantly improve living conditions.

The selection criteria for residential buildings for major repairs are:

- the duration of the use of engineering systems and structural elements;

- assessment of the technical condition of engineering systems and structural elements.

The following types of work are provided for, approved by the Fund for Assistance to the Reform of Housing and Communal Services in agreement with the Ministry of Construction of the Russian Federation, carried out during the overhaul of residential real estate for energy conservation and energy efficiency: insulation and repair of the facade, roofs, repair of internal heating and / or water supply systems, devices for monitoring and regulating energy consumption, repair or replacement of elevators, repair of the basement related to common property, and repair of the foundations of residential buildings [1].

One of the complicating factors in the implementation of energy saving measures is the "rebound effect". Improving energy efficiency during major renovations can lead to behavioral change towards increased consumption. The bottom line is that the gains from

* Corresponding author: ksevrukova@vgasu.vrn.ru 
improved energy efficient technology will be offset by behavioral change, and net energy consumption may paradoxically increase. This is due to the tendency of consumers to consume more energy due to the economic benefits of improved efficiency.

This effect must be taken into account at the stage of developing the implementation of energy efficient measures during the period of major repairs.

The «rebound effect» is measured as the difference between planned and actual savings from efficiency gains. Three types of «rebound effect» can be distinguished.

- - direct effect - the meaning is that the consumer should change the attitude in favor of the most efficient appliances (devices);

- indirect effect - based on increasing the use of energy resources through various technologies or measures;

- -macroeconomic effect - is considered global in nature and has a significant impact on the economy due to the need to use more energy efficient technologies and large energy sources.

This effect can be observed when installing improved thermal insulation of facades or a more efficient heating boiler, it is assumed that they should reduce heating bills. However, if homeowners keep their homes at a higher temperature than before, or heat them for a longer period of time, then the savings can be wholly or partially offset.

The reasons for the rebound effect in the implementation of energy saving measures can be divided into 3 groups:

- economic (increased demand for energy efficient appliances (devices));

- socio-psychological (the need for energy resources is growing, since the attitude towards the devices and / or devices used is changing);

- regulatory (growth in demand as a result of the government encouraging the use of energy efficient equipment).

Economic reasons are the most common and almost impossible to exclude, but it is possible to predict them.

Socio-psychological reasons for the rebound effect can be attributed to the purchase and use of new devices and / or appliances. These reasons are difficult to exclude and almost impossible to predict.

Regulatory reasons arise from programs to support and encourage the use of energy efficient equipment. It is possible to exclude with a rational elaboration of the criteria for state support [2-4].

Studies conducted in various countries $[3,5-8,15-16]$ have shown that the presence of a rebound effect leads to the fact that the expected part of the effect from the introduction of energy-efficient measures is "eaten up", and it is also possible to increase energy consumption instead of reducing (ricochet effect) (fig.1). 


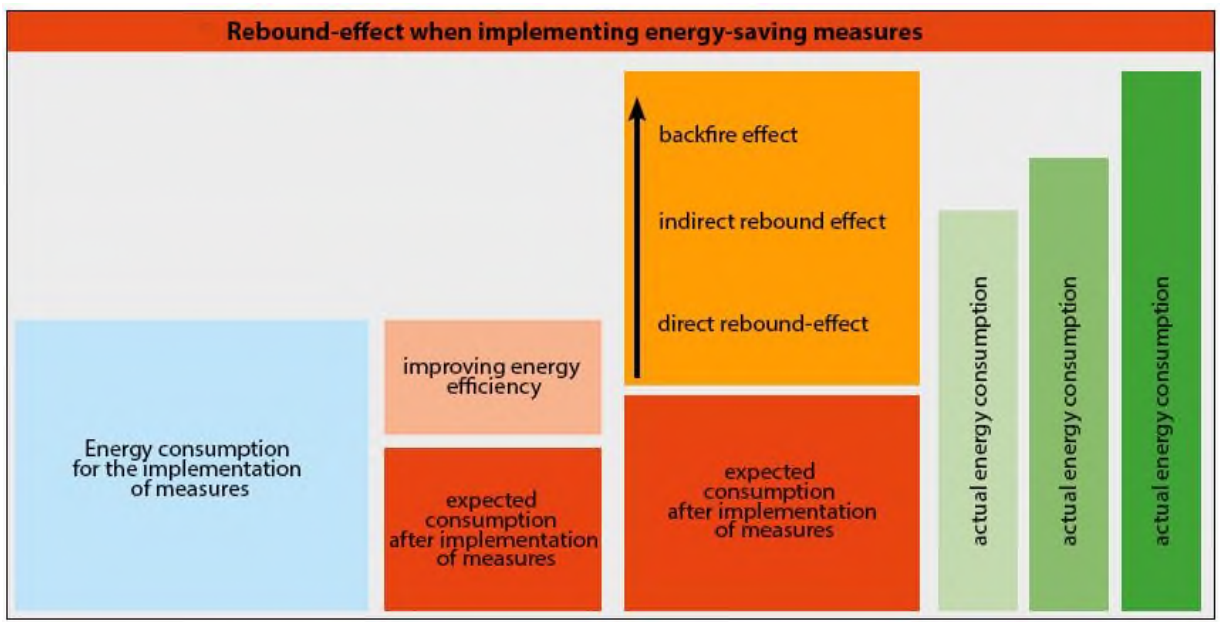

Fig.1. Schematic representation of ricochet and rebound effects [3]

The rebound effect is a term used to characterize a paradox or anomaly in energy conservation policies and programs. Thus, the paradox is that, due to certain reasons, the increase in energy efficiency results in less reduction in energy consumption and / or material resources than expected.

The rebound effect is an increase in energy consumption and / or material resources after the implementation of an energy-saving measure above the initial level.

Reasons for the rebound effect:

- -increasing the intensity of using consuming devices;

- -increase in the number of consuming devices;

- -increase in specific consumption.

The rebound effect is difficult to quantify and is therefore not considered when improving energy efficiency. It is usually expressed as a percentage of the expected energy savings while improving energy efficiency. thus, the effect rebounded by $20 \%$ means that only $80 \%$ of the expected energy savings have been achieved [4].

\section{Materials and methods}

Most of the buildings and utilities were built before the 2000s and therefore require a complete modernization. Without isolation and energy-saving measures, the energy efficiency indicators of obsolete residential real estate are close to zero. The Regional Program for the Major Overhaul of Common Property in apartment Buildings in the Voronezh Region for 2014 - 2044 [2] was approved to improve the energy efficiency of residential real estate. The program consists of a list of repairs to improve the energy efficiency of common property in residential buildings and the period of their implementation. The main energy-saving works were construction and installation work to restore the bearing capacity of the foundation, insulation and repair of the facade, repair of the roof, replacement (repair) of internal engineering systems for heating and water supply, etc. [9].

Consider, as an example of the application of this program, an overhaul residential property located in the city of Voronezh. As a result of the overhaul, the following works were performed: repair of the facade, repair of the drainage system, heat supply system, cold water supply system, hot water supply system, power supply system and roof repair [10].

a)

b) 

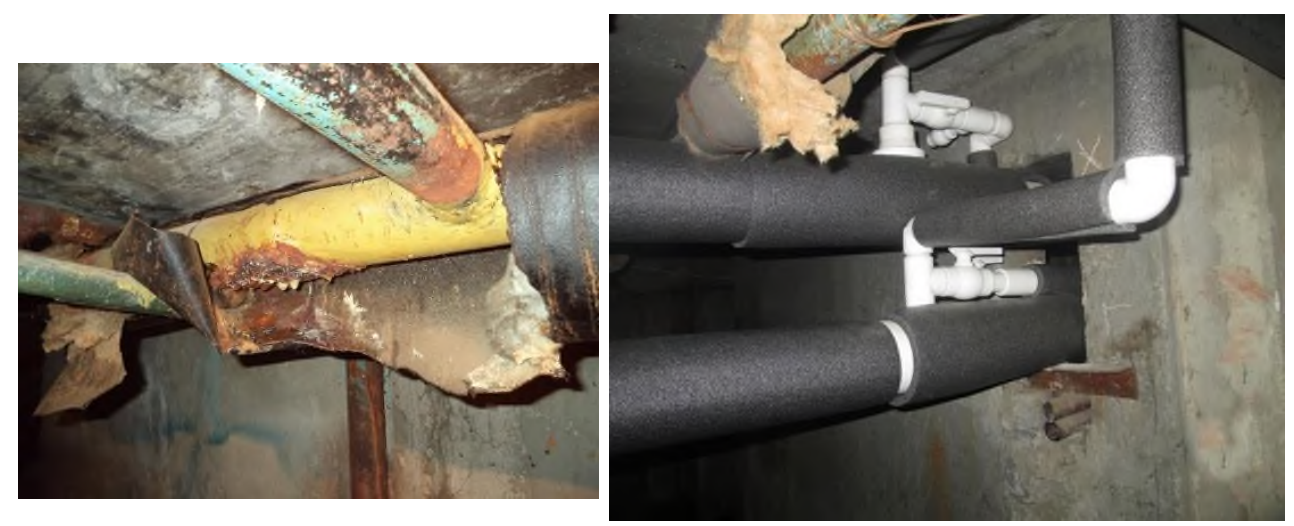

Fig. 2. Heating system of an apartment building: a) before renovation; b) after renovation [10].

After carrying out energy efficient measures, we calculated the energy efficiency class of the building in accordance with BR 50.13330.2012 "Thermal protection of buildings. Updated edition of BRAR 23-02-2003 "[11-12]. As a result of the calculations, the facility was assigned an energy efficiency class $\mathrm{C}$ - normal.

Local estimate calculations were formed and the estimated cost of energy efficiency measures was established to determine the required investments.

As a result, the internal heating system was balanced and the building structures were insulated, as a result of these works, energy savings can reach about $50 \%$.

However, insulation alone cannot improve the energy efficiency of a building and reduce heating costs. The optimal result will be achieved through the modernization of all internal engineering systems.

An energy audit helped to identify the strengths and weaknesses of the building. Thanks to him, measures were selected that reduce the energy consumption of a residential building. The costs for the introduction of energy-saving measures for the comprehensive modernization of a residential property and the payback period were calculated.

As a result of the modernization, each consumer will significantly reduce energy consumption. The cost in the receipt will decrease approximately 2 times, while the payment will slightly increase for the period of loan repayment, but it can be considered an investment in comfort. [13].

Advantages - the residential building will look good, and the apartments will have favorable conditions regardless of the season. The savings will be both in the cold season (heating) and in the warm season (air conditioning), since the houses will not get too hot.

When insulating facades, existing real estate objects, it is also necessary to take into account that buildings erected in accordance with outdated standards (prior to the enactment of the Federal Law "On Energy Saving and Energy Efficiency and on Amendments to Certain Legislative Acts of the Russian Federation" dated 23.11. 2009 N 261-Ф3), are at a low level of thermal protection. In order to meet the new requirements, measures must be taken using modern thermal insulation materials and energy-saving technologies to improve their energy efficiency [14].

Table 1. The sequence of calculating the payback period

\begin{tabular}{|l|l|}
\hline formula & \\
\hline
\end{tabular}




\begin{tabular}{|c|c|}
\hline$T=\frac{K_{2}}{\left(E_{1}-E_{2}\right)}=\frac{\Delta K}{\Delta E}$ & (1) \\
\hline$\Delta E=\left(U_{1}-U_{2}\right) \cdot \frac{0,024 \cdot G S O P}{1163} \cdot c_{T}$ & \\
\hline
\end{tabular}

In this table:

$T$ - payback period, year;

$\Delta K$ - capital costs for the construction of $1 \mathrm{~m}^{2}$ of an external wall - the difference in capital costs reduced to $1 \mathrm{~m}^{2}$ of an external wall, rub. $/ \mathrm{m}^{2}$;

$E_{1}$ - operating costs, taking into account the loss of thermal energy through $1 \mathrm{~m}^{2}$ of the outer wall for one heating season before insulation, rub./( $\mathrm{m}^{2} \cdot$ year $)$;

$E_{2}$ - operating costs, taking into account the loss of heat energy through $1 \mathrm{~m}^{2}$ of the outer wall during one heating season after the walls are insulated, rub. $/\left(\mathrm{m}^{2} \cdot\right.$ year $)$;

$\Delta E$ - annual cost savings achieved as a result of renovation works on the facades of an existing building, rub. $/ \mathrm{m}^{2}$;

$U_{1}$ - heat transfer coefficient (U-value) of the outer walls of an existing building before renovation (insulation) of facades, $\mathrm{W} /\left(\mathrm{m}^{2} \cdot{ }^{\circ} \mathrm{C}\right)$;

$U_{2}$ - heat transfer coefficient (U-value) of the outer walls of an existing building after renovation (insulation) of facades, $\mathrm{W} /\left(\mathrm{m}^{2} \cdot{ }^{\circ} \mathrm{C}\right)$;

GSOP- degree-day of the heating period, ${ }^{\circ} \mathrm{C} \cdot$ day;

$c_{T}$ - the cost of heat energy for heating in a given locality, rubles / Gcal;

To calculate $\mathrm{T}$ (investment payback period) aimed at thermal modernization of residential real estate, the method of "reduced costs" is used, for this we use generalized formulas in accordance with table. 1.

When making calculations, we do not take into account the following indicators:

- increase in tariffs for heat energy;

- interest on the loan (when using borrowed funds to carry out activities for the insulation of the outer walls of the building);

- discounting of future cash flows received as a result of the implementation of the discussed energy saving funds and reduction of heat energy losses for heating.

The planned repayment period of the investment can only be considered as indicative, while it is necessary to take into account the savings in money, this is due to annual inflation and is performed due to discounting. [13].

\section{Results}

$U$ - heat transfer coefficient, for its calculation we assume that the heat transfer resistance of

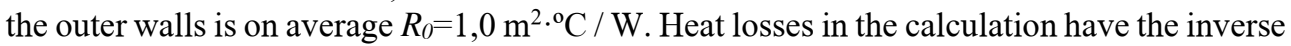
dimension to the reduced heat transfer resistance.

The heat transfer coefficient can be calculated using the formula:

$$
U=1 / R_{0}
$$

Having calculated how much heat energy $(\mathrm{kWh})$ per $1 \mathrm{~m}^{2}$ of the outer wall, it is necessary to multiply the value of the heater operation time by the average temperature for the heating period. Information for this climatic zone is taken into account in accordance with $\mathrm{c}$ «BUILDING CLIMATOLOGY» [12]. 
We obtain the value of the total amount of heat losses $Q$ from the value of $1 \mathrm{~m}^{2}$ of the enclosing structure with the heat transfer coefficient $U=1,0 \mathrm{~W} / \mathrm{m}^{2}{ }^{\circ} \mathrm{C}$ :

$$
Q=\frac{U \cdot\left(t_{v}-t_{o t}\right) \cdot z_{o t} \cdot 24}{1000}
$$

where $t_{v}$ - the air temperature inside the premises of the property, taken according to «

Residential and public buildings. Indoor microclimate parameters»;

$t_{o t}$ - average outside air temperature during the heating season, taken depending on climatic

conditions by [12];

$Z_{o t}$ - number of days of the heating period for residential buildings;

24 - number of hours in a day;

1000 - conversion factor of heat flux from $\mathrm{W}$ to $\mathrm{kW}$.

In accordance with this formula, we find the average losses of heat energy per $1 \mathrm{~m}^{2}$ during the heating period, expressed in $\mathrm{kWh}$. You can convert this value into gigacalories $(1 \mathrm{Gcal}=$ $1163 \mathrm{kWh}$ ).

With this in mind, the formula can be written as:

$$
\begin{aligned}
& Q=\frac{U \cdot\left(t_{v}-t_{o t}\right) \cdot z_{o t} \cdot 24}{1000 \cdot 1163}, \\
& Q=\frac{U \cdot G S O P \cdot 0,024}{1163},
\end{aligned}
$$

If we want to calculate the operating costs $\mathrm{E}\left(1 \mathrm{~m}^{2}\right.$ per wall area) during the heating season, use formula no. 2. In this formula, the result depends on the cost of heat or electricity. Having performed the calculations, we will get the difference in operating costs for the outer wall of the building before and after insulation.

The result is an annual savings in money from work to restore the facade of an existing residential property:

$$
\begin{aligned}
& \Delta E=\left(U_{1}-U_{2}\right) \cdot 0,024 \cdot G S O P / 1163 \\
& =(1 / 1,356-1 / 3,5) \cdot 0,24 \cdot 4275 / 1163=(0,737-0,286) \cdot 0,88 \cdot 2219,5=88,08 \text { rubles } / m^{2}
\end{aligned}
$$

Capital costs $\Delta \mathrm{K}$ for additional insulation during the renovation of an existing property, calculated on the basis of FER 26-01-045-03 and amounts to 1,524.6 rubles $/ \mathrm{m}^{2}$. When using the obtained values of $\Delta \mathrm{K}$ and $\Delta \mathrm{E}$ in the formula, we have an indicator of the simple payback period of thermal modernization of the outer wall of a residential property:

$$
T=\Delta K / \Delta E=1304,6 / 88,08=15 \text { years }
$$

This value is considered only as an estimate, since the increase in tariffs was not taken into account.

To reduce the payback period $\mathrm{T}$ of energy-saving measures, it is necessary to reduce capital costs $\Delta K$ or increase operating $\Delta E$.

Thanks to the calculations and the assessment of the economic efficiency of the project, it is necessary to eliminate the rebound effect.

\section{Discussion}

To exclude the rebound effect, let us determine its quantitative value $R$, which can be calculated by the formula [3]:

$$
R=1-\left(\frac{\Delta E_{f}}{\Delta E_{r}}\right)
$$


where, $\Delta E_{f}$ - the actual change in energy consumption after the implementation of measures to improve energy efficiency;

$\Delta E_{r}$ - estimated change in energy consumption after the implementation of measures to improve energy efficiency.

If $\Delta E_{f}=\Delta E_{r} \rightarrow R=0$, then there is no rebound effect, actually coincided with the expected;

If $\Delta E_{f}<\Delta E_{r} \rightarrow R>0$ - rebound effect is present;

If $\Delta E_{f}<\Delta E_{r} \rightarrow R<0$ - the actual effect exceeded the expected;

If $\Delta E_{f}<\Delta E_{r} \rightarrow R \geq 0$ - ricochet effect appeared [3].

In our situation, when calculating the quantitative value of the rebound effect, we have that $\Delta E_{\phi}=152 \mathrm{kWh} / \mathrm{m}^{2}$

The estimated change in energy consumption after the implementation of measures to improve energy efficiency is $\Delta E_{\mathrm{p}}=138 \mathrm{kWh} / \mathrm{m}^{2}$, in accordance with the baseline values and standardized indicators.

$$
R=1-\left(\frac{152}{138}\right)=-0.1
$$

$\Delta E_{f}>\Delta E_{r} \rightarrow R=-0.1<0$

In our case, the actual effect exceeded the expected, which indicates a worse result than expected.

The European Commission estimates that the impact of «Rebound effect» ranges from 10 to $80 \%$ when implementing energy efficiency measures.

For example, in 2012 German researchers compared the actual energy consumption of 3,400 households in Germany with estimates of energy consumption. It turned out that actual consumption is on average 30 percent lower than the estimated consumption. Particularly significant differences were found in non-rehabilitated, energy efficient building funds and households where no efficiency measures were taken, such as replacing equipment. Here, energy consumption has always been calculated and estimated to be higher than it actually was. The main reason for this discrepancy was the human factor in construction management.

\section{Findings}

During the research, the following were calculated: calculation of the economic efficiency of facade insulation and calculation of the rebound effect. As a result of the calculations, the presence of a rebound effect was noted, which indicates insufficient implementation of the project. Based on this, we can conclude that the consideration of the rebound effect is relevant today and requires its consideration to achieve the planned indicators while increasing the energy efficiency of existing apartment buildings.

This rebound effect can be observed in such areas of the economy as:

- residential sector and household energy consumption;

- construction and maintenance of buildings and structures;

- lighting (public, administrative premises, residential buildings, including street lighting)

- IT infrastructure;

- transport.

When carrying out energy efficient measures in the implementation of programs (municipal, regional, sectoral), it is necessary to take into account the rebound effect (also the emergence of a rebound effect) and try to bring it to minimum values.

The main ways to minimize the rebound effect are proposed in international practice and can be adapted and used for the Russian Federation. 


\section{References}

1. A. V. Raevskaya, Improving energy efficiency during major repairs of apartment buildings, 8 (2016)

2. A. V. Mogilenko, Implementation of resource and energy saving measures. The structure and examples of manifestations of the rebound effect (2018)

3. A. V. Mogilenko, The rebound effect as a deterioration in the result of energy-saving measures in comparison with the expected one (2016)

4. A. V. Mogilenko, D. A. Pavlyuchenko, Experience of energy efficiency networks in Germany (2015)

5. V. Corrado, I. Ballarini, S. Paduos, E. Primo, The rebound effect after the energy refurbishment of residential buildings towards high performances (2016)

6. D. F. Vivanco, S. Sala, W. McDowall, Roadmap to rebound: How to address rebound effects from resource efficiency policy (2018)

7. S. Sorrell, The rebound effect an assessment of the evidence for economy-wide energy savings from improved energy efficiency (2007)

8. Energy efficiency policies and the rebound effect. Review of international instruments and recommendations for Austria (2017)

9. Resolution of the Government of the Voronezh Region dated March 6, 2014, 183 "On approval of the regional program for the overhaul of common property in apartment buildings in the Voronezh Region for 2014 - $2044 \quad$ (2014) http://docs.cntd.ru/document/430639697 (Last accessed 12.12.2020)

10. On the results of the work of the Fund for Overhaul of Apartment Buildings in the Voronezh Region in 2019 (2019)

11. BR 50.13330.2012 Thermal protection of buildings. Updated edition of BRAR 23-022003, 1 http://docs.cntd.ru/document/1200095525 (Last accessed 12.12.2020)

12. BR 131.13330.2018 "BRAR 23-01-99 * Construction climatology" http://docs.cntd.ru/document/554402860 (Last accessed 22.12.2020)

13. A. S. Gorshkov, P. P. Rymkevich, D. V. Nemova, N. I. Batting, Methodology for calculating the return on investment for the renovation of the facades of existing buildings, 2(17) (2014)

14. STST 31167-2009. Buildings and constructions. Methods for determining the air permeability of enclosing structures in natural conditions. http://docs.cntd.ru/document/gost-31167-2009 (Last accessed 22.12.2020)

15. V. Ya. Mishchenko, S. G. Sheina, E. P. Gorbaneva, Increase of energy efficiency during overhaul of housing stock in Russian Federation, IOP Conf. Series: Materials Science and Engineering, 481, 012031 (2019) DOI: 10.1088 / 1757-899X / 481/1/012031

16. V. Mishchenko, E. Gorbaneva, E. Ovchinnikova, K. Sevryukova, Planning the Optimal Sequence for the Inclusion of Energy-Saving Measures in the Process of Overhauling the Housing Stock, Advances in Intelligent Systems and Computing, 983, 79 -91 (2019) DOI: 10.1007 / 978-3-030-19868-8_8 